\title{
ASSESSING THE FACTOR STRUCTURE OF THE SPREITZER'S PSYCHOLOGICAL EMPOWERMENT SCALE AMONG MALAYSIAN TEACHERS
}

\author{
Ahmad Zamri Khairani *, Aziah Ismail, Norliza Abdul Kadir \\ School of Educational Studies, 11800, Universiti Sains Malaysia, Penang, Malaysia \\ *e-mail: ahmadzamri@usm.my
}

\begin{abstract}
Psychological empowerment is one of the compelling factors that drive employees to be more initiative and innovative and Sprietzer's Psychological Empowerment Scale (PES) has been widely used to measure it. Nevertheless, PES stability has not been determined in the Malaysian context, limiting its meaning and interpretation. Hence, this study examines the factor structure of the scale among Malaysian teachers. The scale structure was investigated using confirmatory factor analysis (CFA) simultaneously with the convergent validity, discriminant validity, and reliability assessment. CFA results of factor loadings and average variance extracted revealed significant evidence of convergent validity while the Fornell-Larcker procedure produced an outcome that supported high discriminant validity of the PES. The reasonable values of the goodness-of-fit indices show that overall, the data fit well. Also, based on the values of the composite reliability and the Cronbach's alpha, measurement using the scale demonstrated high internal consistency. Thus, the findings confirmed the stability of the factor structure and therefore provided evidence of generalizability of the scale into the Malaysian context.
\end{abstract}

Keywords: factor structure, psychological empowerment, schoolteachers, confirmatory factor analysis

\section{INTRODUCTION}

In the current global era of intense competition and constant change, it is pertinent that employees must acquire the drive to be more initiative and innovative to persevere in the working environment. Empowerment, which is briefly defined as the freedom given to the employees to make decisions about how they do their duties and tasks (Ford \& Fottler, 1995), is decidedly one of the compelling factors to achieve this. Through empowerment, employees will be more responsible, able to make crucial decisions and be in control of their career development, which in turn will increase the quality of the work, reduce costs, and contribute productively to the organization's collaborative growth. Empowerment has been identified as an essential factor related to positive work-related outcomes such as satisfaction and commitment in an organization (Chan et al., 2015), as well as the driving force to transfer power from management (Kmieciak et al., 2012; Randolph \& Kemery, 2011). This transfer is crucial for the employees to have more authorities over resources, and thus improve their potentials in the work-related environment (Huang, 2012).

Psychological empowerment (PE) refers to an intrinsic motivation regarding employees' selfbelief (Conger \& Kanungo, 1988). With a healthy degree of PE, employees would have more control over their work performance and be more aware of the work context. Employees who lack psychological empowerment, on the other hand, would be unable to feel the value of their job and doubtful about their abilities as well as expertise. At the same time, they do not gain any freedom in decision-making process and will not show any improvement in the performance of their duties. Thus, it is a common belief that PE helps the employee to be more accountable for their assigned work.

Due to its positive relationship with workrelated outcomes, PE has been widely and extensively studied in various organizational settings. For example, in the study involving an international sporting goods distributor, the construct has been shown to be positively correlated with job satisfaction (Chan et al., 2015). Similar results were found in the sample of Norwegian mission organizations (Dewettinck \& van Ameijde, 2011). Wang \& Lee (2009) also reported the same findings for service, retail and distribution, research, and manufacturing organizations. Meanwhile, research by Seibert et al. (2004) as well as Meyerson \& Kline (2008) also explained that PE is positively associated with job performance. Another interesting finding was that $\mathrm{PE}$ has shown as a significant predictor to job burnout and competitive advantage (Livne \& Rashkovits, 2018).

In Besides that, PE was also positively correlated with employees' engagement with their work (Bhatnagar, 2012; Ugwu et al., 2014). Moreover, PE was proven to have a positive correlation with creativity. For instance, Sun et al. (2012) acknowledges that when the 
empowered employees realize how personally meaningful their work is, they are conceivably willing to accomplish and perform better. Likewise, when employees have greater influence over their jobs, they are more open to adopting new ideas and possible solutions (C.-J. Wang et al., 2014).

Meanwhile, PE in education is an important topic among researchers mainly because empowering teachers and educators is of utmost importance in education. This is because empowerent helps teachers nurture a belief that classrooms are really theirs and school administrators have confidence in every teacher to teach the students. Moreover, empowered teachers have the freedom to implement innovative strategies during teaching and learning, which are more exciting and engaging and did not only resort to traditional methods. As for the school leaders, empowered teachers are more motivated and committed to their work roles. Meanwhile, PE in education is an important topic among researchers mainly because empowering teachers and educators is of utmost importance in education. This is because empowerment helps teachers nurture a belief that classrooms are really theirs and school administrators have confidence in every teacher to teach the students. Moreover, empowered teachers have the freedom to implement innovative strategies during teaching and learning, which are more exciting and engaging and did not only resort to traditional methods. As for the school leaders, empowered teachers are more motivated and committed to their work roles (Sagnak, 2012; Simkins, 2005; Vecchio et al., 2010). Showing appreciation or gratitude is not the only means of empowering teachers. More importantly, school leaders should provide teachers with a platform to participate in decisionmaking activities such as designing or planning curriculum, setting goals, etc. In addition, schools should also support empowered teachers through constant monitoring, supervising, and providing constructive feedback. Team building, constant communication, and nurturing positive culture may also work in appreciating teachers' ideas that, in turn, will enable empowerment to thrive in schools (Simkins, 2005; Vecchio et al., 2010). Showing appreciation or gratitude is not the only means of empowering teachers. More importantly, school leaders should provide teachers with a platform to participate in decision-making activities such as designing or planning curriculum, setting goals, etc. In addition, schools should also support empowered teachers through constant monitoring, supervising, and providing constructive feedback. Team building, constant communication, and nurturing positive culture may also work in appreciating teachers' ideas that, in turn, will enable empowerment to thrive in schools.

One of the most widely used instruments to measure PE is the Psychological Empowerment Scale (PES). In developing the instrument, (Spreitzer \& Quinn, 2001) concepttualized PE as a desired construct that manifests in four dimensions, namely, meaning, competence, self-determination, and impact. The four dimensions are conceptualized en masse to define the construct of the PE, which means that the absence of any of the dimensions shall result in an inflated degree of PE. It should also be noted that PE reflects an active orientation towards the working condition. That is, an individual should be able to shape their orientation according to the work environment and not vice versa.

The meaning dimension involves how an individual value their work goal. Every employee in an organization needs to know their roles and responsibilities in their respective jobs for them to value their work. A person's work characteristics can influence the level of meaning experienced in the workplace. Therefore, employees need to develop a sense of pride in their workplace and work abilities. Taking pride in helping the employees to strive for the best among their colleagues and give their all in any tasks assigned to them. Organizations should encourage their employees to look back at their accomplishments and qualities that they have received during work to nurture pride. Sense of meaning can also be nurtured when employees are treated with respect, and his or her contribution is valued (May et al., 2004). Another way to promote a sense of meaning is by treating employees with respect because this will lead the employees to have shared organizational goals (Avolio et al., 2004).

Competence involves one's belief in their capacity to perform tasks. Sense of competencies can be achieved through formal training, selfstudy, diverse experiences, mentoring processes, reflection, access to learning structures and resource centres, and exposure to the broader environment (Forrester, 2000). In addition, employees can also engage in ongoing learning and research programs to improve their job competencies. Thus, through this dimension of competence, empowered employees will feel more inclined to be efficient and as a result, influence work and organization meaningfully. 
Eventually, the experienced will also cause employees to involve in extra-role efforts, act independently, and have a high engagement to the organization (Spreitzer, 1995b).

With regards to self-determination, the dimension involves a sense of choosing to initiate and control acts. Self-determination is necessary to promote empowerment since works that give autonomy and discretion allow employees to meet a wide range of needs. As such, employees with higher levels of self-determination appear to have more satisfaction with their work, family, and life without having to overthink about finding new jobs, and therefore less stress, and less work-family conflicts (Thompson \& Prottas, 2006). Breaugh (Breaugh, 1985) identifies three dimensions of self-determination, namely on (1) method-which involves the degree of order judgment over the procedures at work, (2) schedulingthe ability of the employees in carting progress of their work, and (3) criteria-the degree to which employees have the right to select the criterion for determining their performance. (Scharle \& Szabo, 2000) add that self-determination also include capability of handling personal matters, including the right to make decisions. According to Spreitzer (1995a), self-determination is visible when making decisions, especially when it relates to work methods, procedures, time, and efforts. A conducive work climate is an important factor that helps to enhance employees' self-determination and involvement in performing their duties as well as encouraging them to be more rational in organizing and choosing their actions. Nevertheless, as Spreitzer \& Quinn (Spreitzer \& Quinn, 2001) observed, superiors were shy to relinquish control and adopt autonomy since they fear that the employees will be able to do the right things for the organization.

Meanwhile, the impact is related to the degree to which an employee may influence favorable results at work. It involves individual beliefs that they can influence strategic out-comes, management, and operations in the workplace (Spreitzer, 1995a). In an organization, the role of employees is important because they can use their experiences, new ideas, and efforts to contribute in any way they can. In other words, employee participation helps build within the organization a sense of community and family. Employees with a favorable view in terms of or participation in the organization will become more motivated, more loyal, and care about attaining goals. Perhaps it is not too off the mark to conclude that in the competitive environment we are facing today, the organization's success or failure relies mostly on the employees.

In PES, each set of the dimensions is measured by three items, with all items being worded positively. The construct validity of the original version was examined using the CFA approach. Results show that all items loaded in the intended dimension with standardized factor loading were within the ranges of .54 to .88 estimation and a reasonable model-data fit was also achieved. Satisfactory evidence of the consistency of the measurement was also presented in terms of Cronbach's statistic (Spreitzer, 1995b).

Sprietzer (Spreitzer, 1995b) acknowledges that there is a need to assume three critical aspects of PE in framing the definition. Firstly, PE is a set of dynamic awareness about working conditions and is influenced by the working environment. It is not a personality trait that may be consistent across all contexts and situations. Secondly, like many other psychological traits, PE is dynamic which means people should be viewed as more psychologically empowered or less empowered rather than whether there is a presence of psychological empowerment or not. Thirdly, PE is a work-specific construct and is not generalizable across different situations or cultures.

Spreitzer's PES has been employed in almost all educational studies measuring the PE. For example, Abdullah et al. (2015) study shows that PE was a significant predictor for both job satisfaction as well as job commitment among teachers at school in Malaysia. Meanwhile, in the neighboring country Singapore, PE was found to be positively associated with the principals' perceptions of an immediate supervisor's empowering behaviors (Lee \& Nie, 2017). Apart from the direct relationship, PE was also found to be a significant mediator. Findings from a study by Kõiv et al. (2019) found that the dimension of meaning and impact mediate the influence of perceived leadership empowerment behavior on work-related outcomes among 711 Estonian school teachers. In another study of Iranian English teachers, Khany \& Tazik (2016) found a direct relationship between PE and job satisfaction, while the construct mediates the relationship between trust and job satisfaction (Safari et al., 2020).

The PES was also widely used by researchers in other areas of studies as well. For instance, Turnipseed and VandeWaa (2020) in their study among nurses found a differential re-lationship between the dimensions in Spreitzer's PES and the dimensions of organizational citizenship 
behavior. Meanwhile, Singh and Singh (2019) employed the scale to show the positive influence of PE on organizational citizenship behavior among 297 employees in the eastern India banking sectors. Also in India, a study using teams consisting of managers and supervisors found that PE moderates the relationship between learning orientation and team performance. It is affirmed that higher PE will lead to a stronger connection between learning orientation and team performance (Jha, 2019).

This rubric is more complex as the wording is a continued Despite its widespread usage, there is a lack of attempt to examine the scale's factor structure and the findings remain inconclusive. For example, Kraimer et al. (1999) could not establish a good fit of the theoretical four-factor model. They found that the correlation between self-determination and impact need to be freely estimated. In contrast, Uner and Turan's (2010) study using the Turkish version of the PES shows a good fit between the data and the original fourfactor model. In addition to that, studies also show that not all items on the scale are fit to measure the PE. For example, Albar et al. (2012) found that Item 10 (subscale impact) did not provide enough meaningful information on the $\mathrm{PE}$ among the Spanish nurses. As such, even though the PES was widely accepted as the salient instrument to measure PE, it is essential to test the scale with other samples from different culture to investigate the established evidence of a universally stable factor structure.

\section{METHODS}

The PES was administered to 474 participants consisting of 105 male and 369 female school teachers. The majority of the teachers $(32.7 \%)$ were between the ages of 31 to 40 years old. Most of them hold a bachelor's degree in education $(80.6 \%)$, with smaller numbers holding master's $(9.3 \%)$ and $\mathrm{PhD}(0.2 \%)$ degrees. The remaining $10.0 \%$ of the lecturers hold a teaching certificate. Approximately $40 \%$ of the teachers have been teaching for 11 to 20 years. In this study, we adapted the 12-item of PES by Spreitzer (Spreitzer, 1995b). The scale was translated into the Malaysian language for optimized comprehension. The PES conceptualizes PE as a multidimensional four-factor dimension; meaning, competence, self-determination, and impact (Spreitzer, 1995a). Conceptualization and operationalization of the PES are presented in Table 1.
Initially, we sought permission from Professor Gretchen Spreitzer from the University of Michigan to use the PES. Once the approval was granted, we made several adaptations to the instrument. By engaging a panel of experts consisting of a psychometric lecturer and a psychology lecturer, we translated the instrument into the Malaysian language using a forward translation procedure. In this procedure, we compared the translations by both experts and a consensus was obtained on the final version of the translation. Then, we adapted several items to suit the school teacher background. Before commencing the data collection process, we asked permission from the Malaysia's Ministry of Education, the state education departments, and the district education office. Finally, the questionnaires were sent to schools. We provided a thorough explanation and guidelines to complete the questionnaire to the headmasters and entrusted them to distribute the questionnaires to the teachers. The data collection was completed after three months.

In this study, the PES factor structure was examined using convergent validity and discriminant validity which are the two key aspects of construct validity. Convergent validity includes examining the sharing of an appropriate proportion of variance between indicators (items) of a particular construct (Hair-Jr. et al., 2014). We examine evidence of convergent using several statistics, namely, (1) standardized factor loadings $(\lambda)$, (2) average variance extracted (AVE), and (3) construct reliability (CR), and (4) Cronbach's alpha $(\alpha)$. Standardized factor loading provides evidence on the relationship between the indicators and the construct. High values of standardized factor loadings are intended since it shows that the indicators and the construct measured are highly correlated. Meanwhile, AVE provides information on whether the group of indicators works together to represent a particular construct/dimension. Simultaneously, $\mathrm{AVE}$ and $\mathrm{CR}$ are calculated using the following formula.

$A V E=\frac{\sum_{i}^{n} \lambda^{2}}{n}$

$C R=\frac{\left(\sum_{i}^{n} \lambda\right)^{2}}{\left(\sum_{i}^{n} \lambda\right)^{2}+\sum_{i}^{n} 1-\lambda^{2}}$

with $\lambda=$ factor loading, $n=$ number of items

According to (Hair-Jr. et al., 2014), the intended values of standardized factor loadings and the AVE is .50, while acceptable CR is established if the value is more than .60. At the same time, Cronbach's provides indications on 
the consistency of the measurement, and the value of .70 is considered acceptable (Nunnally, 1978).

Concurrently, the discriminant validity involves examining whether a particular dimension (and its indicators) differs from other dimensions. One of the widely used procedures to determine evidence of discriminant validity of a specific measurement is the criteria forwarded by Fornell \& Larcker (Fornell \& Larcker, 1981). Using these criteria, the dimensions are different if the square roots of the AVEs are higher than the correlation between the constructs. In addition to the evidence for the convergent and discriminant validity, we also provide substantial evidence of model-data fit by providing information on four goodness-of-fit indices. The first fit index to be examined is the normed chi-square $\left(\chi^{2 / d f}\right)$. The intended value for this index is less than 5.00 (Schumacker \& Lomax, 2004). Other fit indices are the Tucker-Lewis (TLI), the comparative fit index (CFI), and the root square mean error of approximation, RMSEA. The intended values for both TLI and CFI are $.90(\mathrm{Hu} \&$ Bentler, 1999), while values between the ranges of .05 to .10 are considered as acceptable for the RMSEA.

\section{FINDINGS AND DISCUSSION}

Table 1. Conceptualization and Operationalization of the PES (Spreitzer, 1995b)

\begin{tabular}{|c|c|c|c|}
\hline Dimension & $\begin{array}{l}\text { No of } \\
\text { Item }\end{array}$ & Definition & Example of Item \\
\hline Meaning & 3 & $\begin{array}{l}\text { The value of work goal involving a balance } \\
\text { between work requirement and beliefs, values, } \\
\text { and behaviors. }\end{array}$ & $\begin{array}{l}\text { 'The work I do is very } \\
\text { important to me.' }\end{array}$ \\
\hline Competence & 3 & Belief in one's capacity to perform tasks & $\begin{array}{l}\text { 'I have mastered the skills } \\
\text { necessary for my job.' }\end{array}$ \\
\hline $\begin{array}{l}\text { Self- } \\
\text { determination }\end{array}$ & 3 & $\begin{array}{l}\text { A sense of having choice in initiating and } \\
\text { regulating actions }\end{array}$ & $\begin{array}{l}\text { 'I can decide on my own how } \\
\text { to go about doing my job' }\end{array}$ \\
\hline Impact & 3 & $\begin{array}{l}\text { The extent to which an individual can influence } \\
\text { desirable outcomes at work }\end{array}$ & $\begin{array}{l}\text { 'My impact on what happens } \\
\text { in my department is large' }\end{array}$ \\
\hline Total & 12 & & \\
\hline
\end{tabular}

Table 2. Standardized Faktor Loading ( $\lambda$ ), AVE, CR, and $\alpha$

\begin{tabular}{|c|c|c|c|c|c|}
\hline Dimension & Item & $\lambda$ & AVE & CR & $\alpha$ \\
\hline \multirow[t]{3}{*}{ Meaning } & 1 & .78 & .60 & .82 & .81 \\
\hline & 2 & .72 & & & \\
\hline & 3 & .82 & & & \\
\hline \multirow[t]{3}{*}{ Competence } & 4 & .88 & .78 & .91 & .91 \\
\hline & 5 & .92 & & & \\
\hline & 6 & .84 & & & \\
\hline \multirow[t]{3}{*}{ Self-determination } & 7 & .78 & .58 & .80 & .80 \\
\hline & 8 & .76 & & & \\
\hline & 9 & .74 & & & \\
\hline \multirow[t]{3}{*}{ Impact } & 10 & .61 & .61 & .82 & .81 \\
\hline & 11 & .88 & & & \\
\hline & 12 & .82 & & & \\
\hline
\end{tabular}


Table 3. The Fornell-Larcker Discriminant Validity

\begin{tabular}{lccccc}
\hline & $\mathbf{1}$ & $\mathbf{2}$ & $\mathbf{3}$ & $\mathbf{4}$ & $\mathbf{A V E}$ \\
\hline 1. Meaning & $\mathbf{. 7 7}$ & .52 & .39 & .47 & .60 \\
2. Competence & & $\mathbf{. 8 8}$ & .48 & .35 & .78 \\
3. Self-determination & & & .76 & .52 & .58 \\
4. Impact & & & .78 & .61 \\
\hline
\end{tabular}

Table 4. Goodness-of-Fit Indices

\begin{tabular}{ccccc}
\hline No. & Indices & Cutoff & Reference & Empirical Values \\
\hline 1. & $\chi 2 /$ df & $<5.00$ & Schumacker \& Lomax (2004) & 2.899 \\
2. & TLI & $>.90$ & Hu \& Bentler (1999) & .957 \\
3. & CFI & $>.90$ & Hu \& Bentler (1999) & .969 \\
4. & RMSEA & $0.05-0.10$ & Browne \& Cudeck (1993) & .063 \\
\hline
\end{tabular}

Finally, Table 4 presents model-data fit evidence for the four-factor model for the PES. All the indices showed satisfactory fit, and therefore, the measurement provided strong evidence that the PES has a stable factor structure in measuring PE among school teachers.

\section{Discussion}

The purpose of the present study was to investigate the factor structure of the PES. The results presented enough evidence that supports Spreitzer's (Spreitzer, 1995a) theoretical fourfactor model of PE. Acceptable factor loadings for all items show a strong relationship between each item with its dimension, providing proof that all items are deemed suitable to measure the $\mathrm{PE}$ in the context of Malaysian teachers. One contributing factor to this positive finding was that all items are relatively long, thus excluding uncertainties regarding the items' meaning by lowering the possibility of the respondents to differ in their tendency to agree with the item. As a result, measurement error for every item is relatively low, contributing to a small percentage of shared variance.

Regarding the test level statistics, the PES also demonstrated an acceptable measurement consistency based on the high value of $\mathrm{CR}$ and Cronbach's $\alpha$, partly due to the high value of standardized factor loadings. Another possible reason for the measurement consistency is the relatively large number of teachers sampled for this study. With enough sample, the measurement will produce small standard errors that directly influence the calculation of reliability indices such as CR and Cronbach's $\alpha$. High value of factor loadings, and a small number of items in this study also contributed to the high value of AVE that indicates acceptable evidence of convergent validity.

In this study, the dimensions of PE were explained within $58 \%$ to $78 \%$ of variance, which is considered as acceptable thus giving the indications that there is a strong relationship between the items and the respective dimensions. The proof of strong discriminant validity between the constructs further confirmed the excellent factor structure of the PES. In other words, meaning, competence, self-determination, and impact were distinct dimensions that help to give meaning to the construct of PE as conceptualized by Spreitzer (Spreitzer, 1995b). All these findings lean towards a conclusion that the PES showed stable factor structure across different cultures. In addition, good fit with the data showed that the scoring method has little influence on the measurement using PES (López et al., 2015; Muris \& Petrocchi, 2017).

Despite not being able to compare the results with other related studies, the rigorous process of validation and the nature of this study itself is distinctly unique. Specifically, the assessment of the factor structure of the scale was carried out on a large national sample. Furthermore, the examination of factor structure was also conducted in line with well-established guidelines. In addition, we have provided a comprehensive yet specific literature review in understanding in the PE explicitly.

While establishing the findings, there are some limitations observed. First, this study lacks a comparison for similar research involving school teachers in other countries. Comparison with results from different cultures might shed some light, especially in providing evidence to support the generalizability of the PES. Second, As the samples were only from school teachers, this research was also limited in terms of generalization. We would recommend future studies to look into assessing the factor structure of the PES among other employees in different organizations and thus establishing the evidence of measurement invariance. Measurement invariance is a vital procedure conducted by researchers (Spreitzer, 1995b; Uner \& Turan, 
2010) to strengthen the evidence of the construct validity of the PES. Future works should also focus on the effort to solidify the evidence of validity by including evidence of predictive validity of the PES. This effort may be undertaken by providing significant evidence of the association between PE and other related outcome variables such as job satisfaction, work commitment, or work engagement.

\section{CONCLUSION}

This study aims to assess the factor structure of the Malaysian adaptation of Spreitzer's PES. In conclusion, we found that the measurement supports the theoretical four-factor PE model, with substantial evidence of convergent and discriminant validity. In addition, this study also provides ample evidence on the consistency of measurement of the PE using the PES. We further conclude that the PES factor structure was stable, and the instrument was valid to measure PE in the Malaysian context.

\section{REFERENCES}

Abdullah, A. G. K., Almadhoun, T. Z., \& Ling, Y.-L. (2015). Psychological empowerment, job satisfaction and commitment among malaysian secondary school teachers. Asian Journal of Educational Research, 3(3), 34-42.

Albar, M.-J., García-Ramírez, M., Jiménez, A. M. L., \& Garrido, R. (2012). Spanish adaptation of the scale of psychological empowerment in the workplace. The Spanish Journal of Psychology, 15(2), 793-800.

https://doi.org/10.5209/rev_SJOP.2012.v1 5.n2.38891

Avolio, B. J., Zhu, W., Koh, W., \& Bhatia, P. (2004). Transformational leadership and organizational commitment: Mediating role of psychological empowerment and moderating role of structural distance. Journal of Organizational Behavior, 25(8), 951-968. https://doi.org/10.1002/job.283

Bhatnagar, J. (2012). Management of innovation: Role of psychological empowerment, work engagement and turnover intention in the Indian context. The International Journal of Human Resource Management, 23(5), 928-951. https://doi.org/10.1080/09585192.2012.65 1313

Breaugh, J. A. (1985). The measurement of work autonomy. Human Relations, 38(6), 551-570.

https://doi.org/10.1177/001872678503800 604

Chan, Y. H., Nadler, S. S., \& Hargis, M. B. (2015). Attitudinal and behavioral outcomes of employees' psychological empowerment: A structural equation modeling approach. Journal of Organizational Culture, Communications and Conflict, 19(1), 24-41.

Conger, J. A., \& Kanungo, R. N. (1988). The empowerment process: Integrating theory and practice. The Academy of Management Review, 13(3), 471. https://doi.org/10.2307/258093

Dewettinck, K., \& van Ameijde, M. (2011). Linking leadership empowerment behaviour to employee attitudes and behavioural intentions. Personnel Review, 40(3), 284-305. https://doi.org/10.1108/004834811111186 21

Ford, R. C., \& Fottler, M. D. (1995). Empowerment: A matter of degree. Academy of Management Perspectives, 9(3), 21-29. https://doi.org/10.5465/ame.1995.950921 0269

Fornell, C., \& Larcker, D. F. (1981). Evaluating structural equation models with unobservable variables and measurement error. Journal of Marketing Research, 18(1), 39-50. https://doi.org/10.1177/002224378101800 104

Forrester, R. (2000). Empowerment: Rejuvenating a potent idea. Academy of Management Perspectives, 14(3), 67-80. https://doi.org/10.5465/ame.2000.446806 7

Hair-Jr., J. F., Black, W. C., Babin, B. J., \& Anderson, R. E. (2014). Multivariate data analysis. In Pearson New International Edition (7th ed.). Pearson Education Limited.

Hu, L., \& Bentler, P. M. (1999). Cutoff criteria for fit indexes in covariance structure analysis: Conventional criteria versus new alternatives. Structural Equation Modeling: A Multidisciplinary Journal, 6(1), 1-55. https://doi.org/10.1080/107055199095401 18 
Huang, J.-T. (2012). Be proactive as empowered? The role of trust in one's supervisor in psychological empowerment, feedback seeking, and job performance. Journal of Applied Social Psychology, 42, E103-E127. https://doi.org/10.1111/j.15591816.2012.01019.x

Jha, S. (2019). Team psychological safety and team performance. International Journal of Organizational Analysis, 27(4), 903924. https://doi.org/10.1108/IJOA-102018-1567

Khany, R., \& Tazik, K. (2016). On the relationship between psychological empowerment, trust, and Iranian efl teachers' job satisfaction. Journal of Career Assessment, 24(1), 112-129. https://doi.org/10.1177/106907271456536 2

Kmieciak, R., Michna, A., \& Meczynska, A. (2012). Innovativeness, empowerment and it capability: Evidence from SMEs. Industrial Management \& Data Systems, 112(5), 707-728. https://doi.org/10.1108/026355712112322 80

Kõiv, K., Liik, K., \& Heidmets, M. (2019). School leadership, teacher's psychological empowerment and workrelated outcomes. International Journal of Educational Management, 33(7), 15011514. https://doi.org/10.1108/IJEM-082018-0232

Kraimer, M. L., Seibert, S. E., \& Liden, R. C. (1999). Psychological empowerment as a multidimensional construct: A test of construct validity. Educational and Psychological Measurement, 59(1), 127142.

https://doi.org/10.1177/001316449959100 9

Lee, A. N., \& Nie, Y. (2017). Teachers' perceptions of school leaders' empowering behaviours and psychological empowerment. Educational Management Administration \& Leadership, 45(2), 260-283. https://doi.org/10.1177/174114321557844 8

Livne, Y., \& Rashkovits, S. (2018).

Psychological empowerment and burnout: Different patterns of relationship with three types of job demands. International
Journal of Stress Management, 25(1), 96108. https://doi.org/10.1037/str0000050

López, A., Sanderman, R., Smink, A., Zhang, Y., van Sonderen, E., Ranchor, A., \& Schroevers, M. J. (2015). A reconsideration of the self-compassion scale's total score: Self-compassion versus self-criticism. PLOS ONE, 10(7), e0132940. https://doi.org/10.1371/journal.pone.0132 940

May, D. R., Gilson, R. L., \& Harter, L. M. (2004). The psychological conditions of meaningfulness, safety and availability and the engagement of the human spirit at work. Journal of Occupational and Organizational Psychology, 77(1), 11-37. https://doi.org/10.1348/096317904322915 892

Meyerson, S. L., \& Kline, T. J. B. (2008). Psychological and environmental empowerment: Antecedents and consequences. Leadership \& Organization Development Journal, 29(5), 444-460. https://doi.org/10.1108/014377308108870 49

Muris, P., \& Petrocchi, N. (2017). Protection or vulnerability? A meta-analysis of the relations between the positive and negative components of self-compassion and psychopathology. Clinical Psychology \& Psychotherapy, 24(2), 373383. https://doi.org/10.1002/cpp.2005

Nunnally, J. C. (1978). Psychometric theory (2nd ed.). McGraw-Hill.

Randolph, W. A., \& Kemery, E. R. (2011). Managerial use of power bases in a model of managerial empowerment practices and employee psychological empowerment. Journal of Leadership \& Organizational Studies, 18(1), 95-106. https://doi.org/10.1177/154805181037979 8

Safari, A., Adelpanah, A., Soleimani, R., Heidari Aqagoli, P., Eidizadeh, R., \& Salehzadeh, R. (2020). The effect of psychological empowerment on job burnout and competitive advantage. Management Research: Journal of the Iberoamerican Academy of Management, 18(1), 47-71. https://doi.org/10.1108/MRJIAM-062019-0935 
Sagnak, M. (2012). The empowering leadership and teachers' innovative behavior: The mediating role of innovation climate. African Journal of Business Management, 6(4). https://doi.org/10.5897/AJBM11.2162

Scharle, A., \& Szabo, A. (2000). Learner autonomy: A guide to developing learner responsibility. Cambridge University Press.

Schumacker, R. E., \& Lomax, R. G. (2004). A beginner's guide to structural equation modeling. Psychology Press. https://doi.org/10.4324/9781410610904

Seibert, S. E., Silver, S. R., \& Randolph, W. A. (2004). Taking empowerment to the next level: A multiple-level model of empowerment, performance, and satisfaction. Academy of Management Journal, 47(3), 332-349. https://doi.org/10.2307/20159585

Simkins, T. (2005). Leadership in education. Educational Management Administration \& Leadership, 33(1), 9-26. https://doi.org/10.1177/174114320504816 8

Singh, S. K., \& Singh, A. P. (2019). Interplay of organizational justice, psychological empowerment, organizational citizenship behavior, and job satisfaction in the context of circular economy. Management Decision, 57(4), 937-952. https://doi.org/10.1108/MD-09-20180966

Spreitzer, G. M. (1995a). An empirical test of a comprehensive model of intrapersonal empowerment in the workplace. American Journal of Community Psychology, 23(5), 601-629. https://doi.org/10.1007/BF02506984

Spreitzer, G. M. (1995b). Psychological, empowerment in the workplace: Dimensions, measurement and validation. Academy of Management Journal, 38(5), 1442-1465. https://doi.org/10.2307/256865

Spreitzer, G. M., \& Quinn, R. E. (2001). A company of leaders: Five disciplines for unleashing the power in your workforce. Jossey-Bass.

Sun, L.-Y., Zhang, Z., Qi, J., \& Chen, Z. X. (2012). Empowerment and creativity: A cross-level investigation. The Leadership
Quarterly, 23(1), 55-65.

https://doi.org/10.1016/j.leaqua.2011.11.0 05

Thompson, C. A., \& Prottas, D. J. (2006). Relationships among organizational family support, job autonomy, perceived control, and employee well-being.

Journal of Occupational Health

Psychology, 11(1), 100-118. https://doi.org/10.1037/10768998.10.4.100

Turnipseed, D. L., \& VandeWaa, E. A. (2020). The little engine that could: The impact of psychological empowerment on organizational citizenship behavior. International Journal of Organization Theory \& Behavior, 23(4), 281-296. https://doi.org/10.1108/IJOTB-06-20190077

Ugwu, F. O., Onyishi, I. E., \& RodríguezSánchez, A. M. (2014). Linking organizational trust with employee engagement: The role of psychological empowerment. Personnel Review, 43(3), 377-400. https://doi.org/10.1108/PR-112012-0198

Uner, S., \& Turan, S. (2010). The construct validity and reliability of the Turkish version of Spreitzer's psychological empowerment scale. BMC Public Health, 10(1), 117. https://doi.org/10.1186/14712458-10-117

Vecchio, R. P., Justin, J. E., \& Pearce, C. L. (2010). Empowering leadership: An examination of mediating mechanisms within a hierarchical structure. The Leadership Quarterly, 21(3), 530-542. https://doi.org/10.1016/j.leaqua.2010.03.0 14

Wang, C.-J., Tsai, H.-T., \& Tsai, M.-T. (2014). Linking transformational leadership and employee creativity in the hospitality industry: The influences of creative role identity, creative self-efficacy, and job complexity. Tourism Management, 40, 79-89.

https://doi.org/10.1016/j.tourman.2013.05 .008

Wang, G., \& Lee, P. D. (2009). Psychological empowerment and job satisfaction. Group \& Organization Management, 34(3), 271296.

https://doi.org/10.1177/105960110833008 9 